\title{
Sizing Efficiency of AKD in Causticizing Calcium Carbonate Filled Paper
}

\author{
Jian Wang ${ }^{1,2^{\dagger}}$, Ling Liu ${ }^{1}$ and Yong-jian $\mathrm{Xu}^{1}$ \\ Received May 12, 2013; Received in revised form February 23, 2014; Accepted March 13, 2014
}

\begin{abstract}
Causticizing calcium carbonate (CCC) is produced as a by-product in the causticization step of the kraft pulping process. It is often calcined in a rotary lime kiln after being dewatered and reused in the causticizing process. But for the China mill, the conventional recycled way is difficult because the CCC is mainly obtained from non-wood pulping materials, which higher silicon content led to serious silicon obstacle. So it is often discarded as solid waste or used in landfill after dewatering and secondary pollution is brought. In order to prevent its secondary pollution, recent years, the CCC is used as a filler in China papermaking industry. In mill trials, the $\mathrm{CCC}$ can be used to replace an amount of precipitated calcium carbonate (PCC). Unfortunately, the application scope and dosage of CCC have been limited due to its lower sizing efficiency than PCC. In this study, the reason for the lower sizing efficiency of alkyl ketene dimer (AKD) when CCC was used as a filler was investigated. The results showed that the materials in green liquid, such as insoluble matter in green liquid, silicon and metal ions, were a little influence on the sizing efficiency of AKD. The higher BET and BJH pore volume of the CCC were the main reason for lower sizing efficiency of AKD when it was used as filler.
\end{abstract}

Keywords : Causticizing calcium carbonate, sizing efficiency, AKD, filler

\section{Introduction}

In the alkali recovery process, it must be to do that the sodium carbonate $\left(\mathrm{Na}_{2} \mathrm{CO}_{3}\right)$ in green liquor is converted into active sodium hydroxide

Slaking: $\quad \mathrm{CaO}+\mathrm{H}_{2} \mathrm{O} \rightarrow \mathrm{Ca}(\mathrm{OH})_{2}$

Causticizing: $\mathrm{Na}_{2} \mathrm{CO}_{3}+\mathrm{Ca}(\mathrm{OH})_{2} \rightarrow 2 \mathrm{NaOH}+\mathrm{CaCO}_{3}$

The causticizing process has two targets, which are obtained from separating the causticized liquor. One is the white liquor containing mainly $\mathrm{NaOH}$. The other is causticizing calcium carbonate (CCC), One is the white liquor containing mainly $\mathrm{NaOH}$. The other is causticizing calcium carbonate (CCC), known as "lime mud" or "lime sludge". The white liquor can be reused to cooking process of plant. The lime mud, for wood materials, after dewatered, can be calcined in a

- 1 College of light industry and energy, Shaanxi University of Science \& Technology Xi'an 710021, China

2 State Key Laboratory of Pulp and Paper Engineering, South ChinaUniversity of Technology Guangzhou, 510640, China

$\dagger$ Corresponding author : E-mail : zzwangjian@sust.edu.cn 
rotary lime kiln and reused in the causticizing process. But for non-wood materials, this recycled way is limited due to the serious silica problems (1). In order to reach the same calcination performance as wood materials $\mathrm{CCC}$, some technologies such as desilication of green liquor (2) and (3) are researched. But unfortunately, those technologies can not solve the silica problems completely. So the lime mud from the non-wood materials is often discarded as solid waste or filled bury field after dewatering. The secondary pollution occurs due to a small amount of $\mathrm{Ca}(\mathrm{OH})_{2}$ in the lime mud. as a kind of $\mathrm{CaCO}_{3}$, can be used as paper fillers which can bring appreciable environment (4-5). In this way, Nanri and Konno (6-9) had made many efforts to control the morphology of CCC and reduce paper-machine plastic wire abrasion. They found that $\mathrm{CCC}$ can be obtained in various forms such as rice-, spindle-, and needle-like particles, some of which demonstrated high opacifying ability and little plasticwire abrasion when used as paper fillers. In china, several lines of CCC filler are completed and the CCC has been used as filler in paper. From the mill trials (10-12), the CCC can be used to replace an amount of PCC, but unfortunately, reducing dosage of CCC had to be adopted because it's higher influence on sizing efficiency of AKD than that of PCC. Now, many research works have been focused on PCC or GCC for its influence on sizing efficiency of AKD (13-15) but they did not involve the CCC. In the present study, the factors influencing the sizing efficiency of AKD in CCC filled paper were investigated in order to provide technical support for quality improvement of CCC in an alkali recovery.

\section{Materials and Methods}

\subsection{Material}

(as shown in Table 1), quicklime, PCC, AKD size (15\% solids content), needle bleached kraft pulp (NBKP), laubholz bleached kraft pulp(LBKP) and cationic polyacrylamide(CPAM) were all obtained from a mill in China. Three kinds of mill CCC were obtained from three mills in mills in China. The properties of PCC and CCCs, tested accordance with Chinese National Standards, ${ }^{16)}$ are shown in Table 2.

\subsection{Preparation of CCC}

Quicklime was added to a flask, which was filled with water and at $300 \mathrm{rpm}$ to achieve slaking. Then the green liquor that was filtered by slow filter paper (Grade 1575) was added to the flask at a constant rate with a transfusion tube, and the causticizing reaction was carried out. The molar ratio of $\mathrm{Ca}: \mathrm{CO}_{3}{ }^{2-}$ was 1.05:1. The reaction temperature was $90^{\circ} \mathrm{C}$. The reaction time was $2 \mathrm{~h}$. After these reactions, the CCC was filtered and washed out with water, then deliquated to $20 \%$ and injected $\mathrm{CO}_{2}$ until the $\mathrm{pH}$ was in the range of 9.5 to 10 . After carbonation, the CCC passing 800 meshes was washed out with water and

Table 1. Main components of mill green liquor

\begin{tabular}{ccccc}
\hline & $\mathrm{Na}_{2} \mathrm{CO}_{3}$ & $\mathrm{NaOH}$ & $\mathrm{SiO}_{2}$ & $\begin{array}{c}\text { Insoluble } \\
\text { matter }\end{array}$ \\
\hline Content $\left(\mathrm{g} \cdot \mathrm{L}^{-1}\right)$ & 138.21 & 28.65 & 6.45 & 2.36 \\
\hline
\end{tabular}

Table 2. The properties of PCC and CCCs

\begin{tabular}{ccccccc}
\hline No. & materials & $\begin{array}{c}\text { Brightness } \\
(\% \text { ISO })\end{array}$ & $\begin{array}{c}\text { Ave. particle size } \\
\text { (um) }\end{array}$ & $\begin{array}{c}\text { Content of } \\
\mathrm{CaCO}_{3}(\%)\end{array}$ & $\mathrm{pH}$ Value & $\begin{array}{c}\text { Acid sediment } \\
\text { volume }\left(\mathrm{mL} . \mathrm{g}^{-1}\right)\end{array}$ \\
\hline 1 & PCC & 92.80 & 4.03 & 97.56 & 9.73 & 0.8 \\
2 & CCC 1\# & 88.36 & 4.38 & 92.33 & 9.32 & 2.4 \\
3 & CCC 2\# & 85.22 & 5.15 & 93.43 & 9.90 & 2.3 \\
4 & CCC 3\# & 87.35 & 5.03 & 92.50 & 10.23 & 2.6 \\
\hline
\end{tabular}


used as filler.

\subsection{Determination of physical properties of $\mathrm{CCC}$}

The determination of particle size was carried out using a BT-9300H laser particle size analyzer. The determination of BET and $\mathrm{BJH}$ was carried out according to an Autosorb-iQ.

\subsection{Adsorption of AKD}

The experiment designed in two steps. In the first step, using an ultraviolet spectrophotometer, the absorbance of different concentrations of AKD was determined at a wavelength of $238 \mathrm{~nm},{ }^{17)}$ and the standard curve of concentration of AKD and absorbance was drawn. In the second step, AKD was appended into the CCC suspension in a ratio 1:100 (AKD: $\mathrm{CCC}$ ) and stirred for 5 minutes. Then, the mixture was centrifuged for 10 min in the centrifuge at $3000 \mathrm{rpm}$. The supernatant liquor was used to determine the absorbance at the wavelength of $238 \mathrm{~nm}$. The content of AKD in supernatant liquor was calculated according to the standard curve. The AKD adsorbed by CCC was equal to the difference between the dosage of AKD and the content of $\mathrm{AKD}$ in the supernatant liquor.

\subsection{Sheet forming}

The $0.2 \% \mathrm{AKD}$ ( to dry stock ) was added to the dispersed stock after $60 \mathrm{~s}$ stirring, and 30\% PCC (to total paper ) or CCC was added. Then, $0.03 \%$ CPAM (to total paper) was added after $30 \mathrm{~s}$ stirring, the stock was poured into the sheet form and handsheets were prepared with a basis weight of $80 \mathrm{~g} / \mathrm{m}^{2}$. The wet paper had pressed for $3 \mathrm{~min}$ under the pressure of $4 \mathrm{kgf} / \mathrm{cm}^{2}$ and dried $5 \mathrm{~min}$ at $95^{\circ} \mathrm{C}$.

\section{Results and Discussion}

\subsection{Sizing efficiency of AKD in CCC filled paper}

The sizing efficiency of AKD in CCCs or PCC filled paper is shown in Table 3.

Compared with that of $\mathrm{PCC}$ filler, the $\mathrm{Cobb}_{60}$ values of paper filled with CCC fillers were higher. That displayed the lower sizing efficiency of AKD. Three kinds of CCC displayed the approximate result. The results showed that there must be differences in the properties of CCC and PCC, which caused the lower sizing efficiency of AKD in the CCC-filled paper.

\subsection{The influence of insoluble matter}

The green liquor and clarified green liquor were used to prepare the $\mathrm{CCC}$ with the same conditions. The basic properties of $\mathrm{CCC}$ and the $\mathrm{Cobb}_{60}$ values of paper filled with CCC are shown in Table 4.

We can know that the insoluble matter in green liquor just affected the brightness of $\mathrm{CCC}$ which had a the brightness of paper, but had no obviously influence on the sizing efficiency of AKD when it was used as filler.

\subsection{The influence of silicon}

The clarified green liquor was treated with sol-gel method treatment and obtained the treated green liquor. ${ }^{18)}$ Two kinds of green liquor were tested the Tyndall

Table 3. Sizing efficiency of AKD in filled paper

\begin{tabular}{|c|c|c|c|c|}
\hline f filler & PCC & CCC $1 \#$ & CCC 2\# & CCC 3\# \\
\hline Cobb60 (g & 24. & 70.2 & 86.1 & 123. \\
\hline
\end{tabular}

Table 4. Basic properties of CCCs and the sizing efficiency of AKD

\begin{tabular}{ccccc}
\hline No. & Source of $\mathrm{CO}_{3}{ }^{2-}$ & Brightness of CCC (\%ISO) & Ave. particle size (um) & Cobb60 $\left(\mathrm{g} \cdot \mathrm{m}^{-2}\right)$ \\
\hline 1 & green liquor & 79.65 & 6.35 & 79.6 \\
2 & clarified green liquor & 90.07 & 5.87 & 82.2 \\
\hline
\end{tabular}




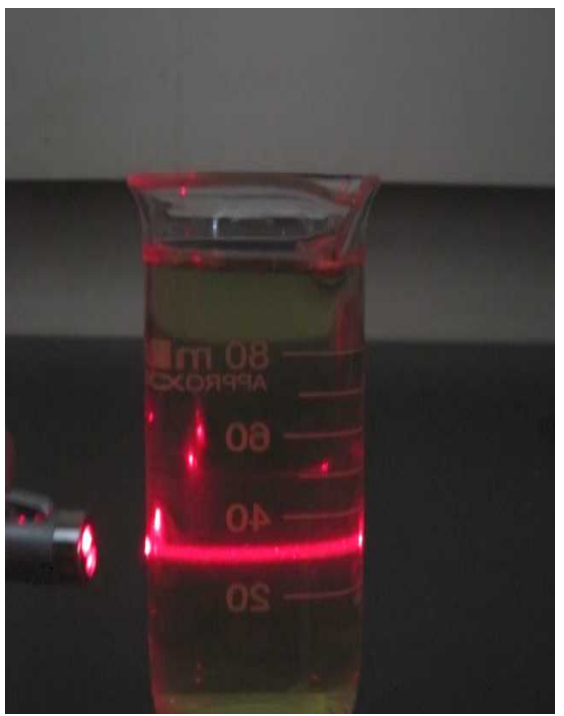

Fig. 1. Tyndall effect of clarified green liquor.

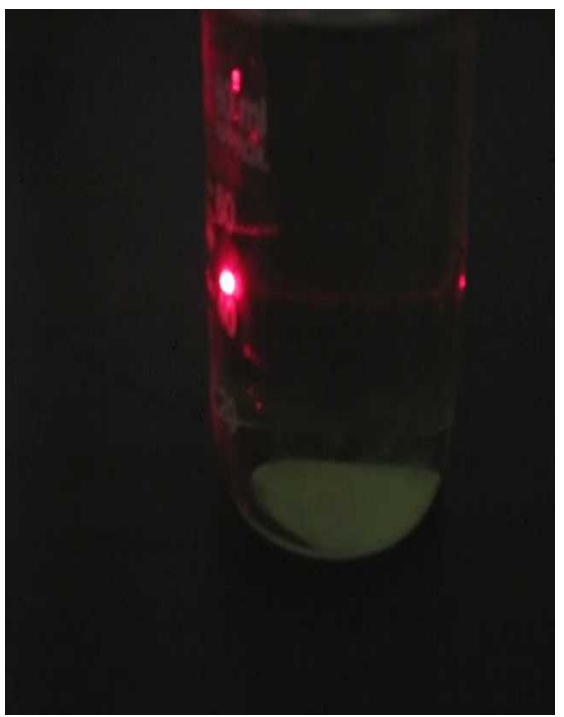

Fig. 2 Tyndall effect of clarified green liquor after sol-gel method treatment.

effect, as Fig. 1 and Fig. 2. From the Fig. 1, there is colloid in clarified green liquor due to the Tyndall effect showing. When the clarified green liquor was treated with sol-gel method, the Tyndall effect is disappeared (as Fig. 2). The experiment was illuminated that the colloid in clarified green liquor was removed by solgel method treatment. Measured the silicon content of two kinds of green liquor, we found, along with the silicon dioxide content of sol-gel treated clarified green liquor was decreased from $6.45 \mathrm{~g} / \mathrm{L}$ to $1.06 \mathrm{~g} / \mathrm{L}$. Meantime, The main component of above sol-gel derived powders was silicon. So the silicon in green liquor had been existed as a colloidal state. The two kinds of green liquor were used to prepare the CCC with the same conditions. When it was used as filler, the $\mathrm{Cobb}_{60}$ values of paper filled CCC are shown as Table 5.

Although the silicon dioxide content contained in two kinds of green liquor were obviously different (6.45 g/L vs. $1.06 \mathrm{~g} / \mathrm{L})$, the $\mathrm{Cobb}_{60}$ values of paper filled CCC were similar. The results illuminated that the silicon had no influence on the sizing efficiency of $\mathrm{AKD}$. The reason may be due to the fact that the silicon was existed the inside of $\mathrm{CCC}$, not the surface.

\subsection{The influence of other element in clarified green liquor}

The clarified green liquor was dried at $60^{\circ} \mathrm{C}$, and and ground into powder. The powder was tested with EDX as Fig.3.

The elements which contained in the clarified green liquor are not only $\mathrm{Na}, \mathrm{O}, \mathrm{C}, \mathrm{Si}$ but also $\mathrm{Cl}, \mathrm{P}, \mathrm{S}, \mathrm{K}, \mathrm{Cu}$ and so on. In order to analysis the influence of other elements on property of $\mathrm{CCC}$ which decreased the sizing efficiency of AKD. The $\mathrm{Na}_{2} \mathrm{CO}_{3}$ (AR, analytical reagent) and the $\mathrm{NaOH}(\mathrm{AR})$ were used to simulate the

Table 5. Basic properties of CCCs and the sizing efficiency of AKD

\begin{tabular}{ccccc}
\hline No. & Source of $\mathrm{CO}_{3}^{2-}$ & $\begin{array}{c}\text { Brightness of CCC } \\
(\% \mathrm{ISO})\end{array}$ & Ave. particle size (um) & $\mathrm{Cobb}_{60}\left(\mathrm{~g} \cdot \mathrm{m}^{-2}\right)$ \\
\hline 1 & clarified green liquor & 90.07 & 5.87 & 82.2 \\
2 & sol-gel treated clarified green liquor & 90.34 & 5.19 & 80.1 \\
\hline
\end{tabular}




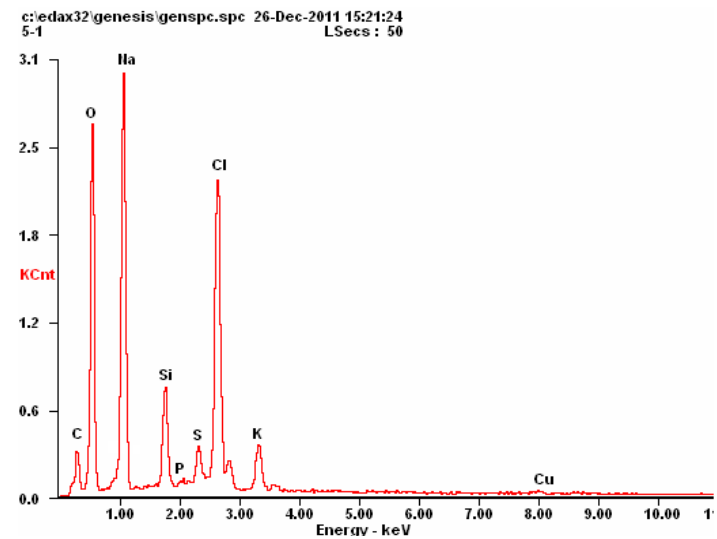

Fig. 3. the EDX of the powder made from dried clarified green liquor.

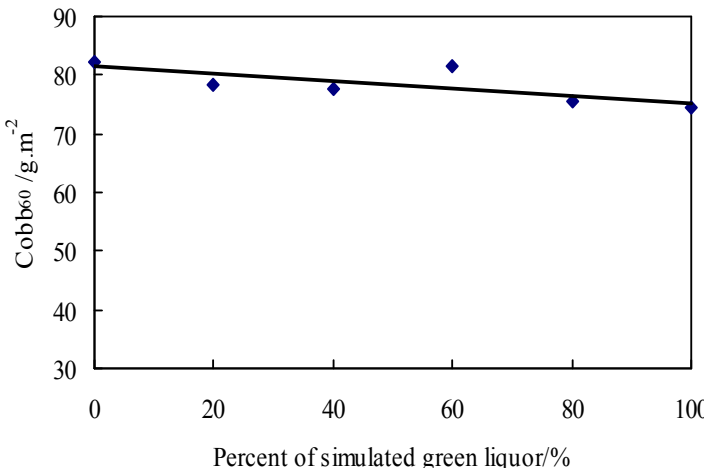

Fig. 4. Effect of pretreatment of raw material for sizing performance.

clarified green liquor according to its content in mill green liquor. The clarified green liquor was mixed with simulated green liquor at different ratio, and the CCCs were prepared with the same conditions. The $\mathrm{Cobb}_{60}$ values of paper filled with CCC are shown in Fig. 4.

There are no elements of $\mathrm{Cl}, \mathrm{P}, \mathrm{S}, \mathrm{K}, \mathrm{Cu}$ in $\mathrm{Na}_{2} \mathrm{CO}_{3}$ (AR) or $\mathrm{NaOH}$ (AR), sothe mixture which mixed the simulated green liquor with clarified green liquor is equivalent to decrease those of elements. From the Fig.4, the $\mathrm{Cobb}_{60}$ values of paper filled CCC are no obviously different, so we thought that the other elements had been no influence on the sizing efficiency of AKD.

\subsection{The influence of $\mathrm{CCC}$}

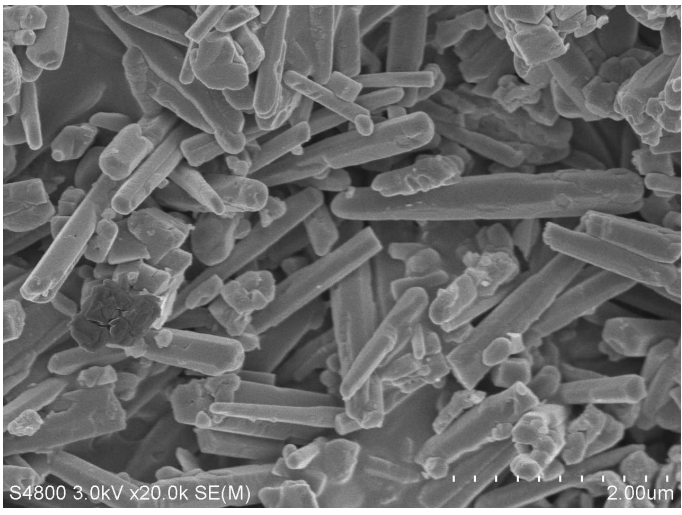

Fig. 5. SEM photographs of Needle-like CCCCs $(20000 \times)$.

Table 6. the properties of fillers and the $\operatorname{Cobb}_{60}$ values of filled paper

\begin{tabular}{cccc}
\hline No. & Type of filler & $\begin{array}{c}\text { Ave. particle } \\
\text { size }(\mathrm{um})\end{array}$ & $\begin{array}{c}\mathrm{Cobb}_{60} \\
\left(\mathrm{~g} \cdot \mathrm{m}^{-2}\right)\end{array}$ \\
\hline 1 & PCC & 4.03 & 24.3 \\
2 & Needle-like CCC & 4.42 & 20.2 \\
\hline
\end{tabular}

By precisely controlling the causticizing reaction as Yasunori ${ }^{19)}$ and Wang's research, ${ }^{20)}$ the needle-like CCCs were prepared as Fig. 5. When it was used as filler, we surprised to find that the $\mathrm{Cobb}_{60}$ value of paper filled CCC was approximately that of PCC, as shown in Table 6.

There is no obviously different ave. particle size between PCC and needle-like CCC. But the sizing efficiency of AKD in the CCC-filled paper was enhanced significantly. The results showed that there must be some changes occurred in the properties of CCC with the change of its micromorphology. The physical properties of fillers are shown in Table 7.

From the Table 7, the ave. particle size of mill CCC $2 \#$ or irregular CCC is a little bigger than that of PCC or needle-like CCC, but, compared with PCC or needle-like CCC, both its BET and BJH pore volume are increased to about 3 times. The higher BET of filler, the more $\mathrm{AKD}$ is adsorbed. The AKD that is adsorbed by the filler will become spreading AKD molecules and migrate into the void structure of the 
pore of CCC in drying process. Meanwhile, a portion of the AKD molecules in contact with surface of CCC can also migrate into the void structure in the drying process. Those AKD are then unavailable for sizing. ${ }^{21)}$ That provides an explanation why there has lower sizing efficiency when conventional CCC is used to fill the paper. So controlling the BET and the BJH pore volume of the $\mathrm{CCC}$ are effective way to improve the sizing efficiency of the CCC filled paper.

\section{Conclusions}

In this study, the results showed as following;

- The materials in green liquid, such as insoluble matter in green liquid, silicon and metal ions, were a little influence on the sizing efficiency of AKD.

- The higher BET and BJH pore volume of the CCC were the main reason for lower sizing efficiency of AKD when it was used as filler.

\section{Acknowledgements}

This paper was supported by the Twelfth Five-Year National Science and technology support program of China (Grant No. 2012BAD23B02), the China State Key Laboratory of Pulp and Paper Engineering Fund (Grant No. 201153) and the Shaanxi University of Science and Technology Scientific Research Fund (BJ12-16).

\section{Literature Cited}

1. Tutus A. and Eroglu H., An alternative solution to the silica problem in wheat straw pulping, Appita 57 (3): 214-217(2004).

2 W. Chute, S. Vichnevsky. Chemimechanical Desilication of Nonwood Plant Materials, United States Patent No. 7364640 ( 2008).

3 Pekarovic J, Pekarovicova A, Fleming III P D., Twostep straw processing - a new concept of silica prob- lem solution, 2006 Engineering, Pulping and Environmental Conference pp.5-8.

4. Yan-jun Tang, Bin-yue Liu, An Overview of Comprehensive Utilization of White Mud, Word Pulp and Paper 22(6):53-55(2003).

5. H.Nurmesniemi, Calcium carbonate waste from an integrated pulp and paper mill as a potential liming agent, Environ Chem Lett 6(1):47 - 51(2008).

6. Haruo Konno, Hideyuki Goto, Kazuto Takahashi, An Innovative Process to Manufacture Calcium Carbonate by the Causticizing Process in a Kraft Pulp Mill, Tappi PaperCon'09 Conference, St. Louis,Pp. 1-18(2009).

7. Nanri Y, Konno H, Goto H., Development of Manufacturing Process for High Quality Calcium Carbonate by Causticizing Process in a Kraft Pulp Mill (Part 1)Fundamental Study on the Controlling Method of Calcium Carbonate Morphology, Japan Tappi Journal 60(11):100-121(2006).

8. Konno H, Nanri Y, Goto H, Development of Manufacturing Process for High Quality Calcium Carbonate by Causticizing Process in a Kraft Pulp Mill-Part 2: Controlling Factors for Precipitation of Aragonite, Japan Tappi 61(3):340-349(2007).

9. Nanri Y, Konno H, Goto H, Development of Manufacturing Process for High Quality Calcium Carbonate by Causticizing Process in a Kraft Pulp Mill (Part 3)Scale-up Trials at Pilot and Mill Plant for Rice-like Particles, Japan Tappi Journal 61(11):58-69(2007).

10. Wang Jin, Yang Peng, Properties evaluation and application performance of white sludge from alkali recovery, Paper and paper making 30(11):51-54(2011).

11. Gui-hua Pan, Jin-shan Chen, Wang-lan Li, Straw Lime Mud as Filler of Paper, Paper and Paper Making 28(7):52-54(2009).

12. Gui-lin Wang, Practise of Straw CCC as Filler of Paper, The Chinese Paper Industry 29 (2) :55-60(2008).

13. A. Karademir;Y. S. Chew;R. W., Hoyland;H. Xiao. Influence of Fillers on Sizing Efficiency and Hydrolysis of Alkyl Ketene Dimer, The Canadian Journal of Chemical Engineering 83(3):603-606(2005).

14. Tom Lindstrom, Gunborg Glad Nordmark, A Study of AKD-sizing Retention- Reaction and Sizing Efficiency, STFI-Packforsk( 2007).

15. A Karadem R., Quantitative determination of alkyl 
ketene dimer(AKD)retention in paper made on a pilot paper machine, Turkish Journal of Agriculture and Forestry 26(5):253-260(2002).

16. Shu-lan Shi, Analysis and detection of pulping and papermaking, Beijing: China Light Industry Press (2003)

17. Bobu E., Old and new aspects on the AKD sizing system, Wochenblatt für Papierfabrikation 128(14-15): 976-981(2000).

18. Zhang Yong-qi, Li Xiao-feng, Xu Yong-jian, Silica removal from green liquor with aluminum sulfate in alkali recovery process of wheat straw pulping, China Pulp \& Paper Industry, 34(18):26-28(2013).
19. Yasunori Naari, Haruo Konno, Hideyuki Goto, A new process to produce high quality PCC by the causticizing processin a kraft pulp mill, Tappi Journal 7(5): 19-24(2008).

20. Jin Wang, Peng Wei, Peng Liu, Identifying Appropriate Conditions for Producing Spindle-like Causticizing Precipitated Calcium Carbonate for Paper Filler Applications, BioResources 7(4):5894-5903(2012).

21. Lindstrom T, O'Brien H., On the mechanism of sizing with alkyl ketene dimmers part 2 the kinetics of reaction between alkyl ketene dimmers and cellulose, Nordic Pulp Paper Res. J. 1(1):34-47(1986). 